\title{
DEMANDA DE POTÊNCIA DE UMA SEMEADORA COM DOIS TIPOS DE SULCADORES EM ÁREAS COMPACTADAS PELO PISOTEIO DE ANIMAIS NO SISTEMA INTEGRAÇÃO LAVOURA-PECUÁRIA ${ }^{1}$
}

\section{VERUSCHKA R. M. ANDREOLLA ${ }^{2}$, ANTONIO GABRIEL FILHO ${ }^{3}$}

RESUMO: O objetivo deste trabalho foi avaliar a potência requerida na barra de tração do trator por uma semeadora com dois tipos de elementos sulcadores, na semeadura da soja, em áreas compactadas pelo pisoteio de animais em sistema de integração lavoura-pecuária. Foi utilizado o delineamento em parcela subdividida inteiramente casualizado, sendo os tratamentos principais compostos de solo úmido com pastejo, solo seco com pastejo e solo sem pastejo, e nos secundários foram utilizados sulcadores de haste ou discos duplos. Foram avaliadas a densidade e a resistência do solo à penetração, a força de tração exercida pela semeadora, a velocidade e a potência requerida na barra de tração do trator. As alterações no solo causadas pelo pisoteio do gado não foram suficientes para interferir na demanda de potência. Entre os elementos, as semeadoras com sulcadores de disco exerceram menor força de tração, e a velocidade de deslocamento do conjunto foi maior.

PALAVRAS-CHAVE: máquinas agrícolas, tração, soja.

\section{SOIL COMPACTION AND POWER OF ONE PLANTER WITH TWO TYPES OF SOWERS IN THE SYSTEM INTEGRATION CATTLE-RAISING AGRICULTURE}

\begin{abstract}
The aim of this work was to evaluate the power required in the drawbar of a seeder with two types of soil opening seed placement in soybean sowing, in areas compacted by the trample of animals in the system of integration cattle-raising agriculture. The experiments was performed in a complete randomized split-plot design, being the mean treatments moisture soil with pasture; dry soil with pasture and soil without pasture, and the secondary treatments hoe opener and staggered doubles-discs opener. The bulk density, cone index, drawbar, speed and power in the drawbar and engine were evaluated. The alterations in the physical properties of the soil, caused by the trampling of the cattle they were not enough to interfere in the power demand. Among the mechanisms, the planters with staggered doubles-discs opener exercised smaller traction force and larger speed.
\end{abstract}

KEYWORDS: agricultural machines, draft, soybean.

\section{INTRODUÇÃO}

O processo de compactação resulta da ação de forças mecânicas, vindas do tráfego de máquinas e/ou do pisoteio de animais sobre o solo e da ação da água de percolação no perfil do solo, transportando partículas dispersas (KOCHHANN et al., 2000).

Durante as operações de preparo do solo e semeadura, são aplicadas forças compactativas que afetam a resistência do solo à penetração (VOORHEES et al., 1989), o que ocorre devido às modificações das condições físico-químicas e biológicas. A resistência à penetração é resultante de forças de coesão entre as partículas do solo, que é definida principalmente pela densidade, do teor de água e da granulometria do solo.

\footnotetext{
${ }^{1}$ Extraído da dissertação de mestrado do primeiro autor.

${ }^{2}$ Eng $^{\mathrm{a}}$ Agrônoma, Mestre em Engenharia Agrícola, Universidade Estadual do Oeste do Paraná, Câmpus de Cascavel - PR, Fone: (0XX45) 3224.2960,vandreolla@yahoocom.br

${ }^{3}$ Eng ${ }^{0}$ Agrônomo, Prof. Adjunto, Universidade Estadual do Oeste do Paraná, Centro de Ciências Exatas e Tecnológicas, Cascavel PR.

Recebido pelo Conselho Editorial em: 3-11-2005
}

Aprovado pelo Conselho Editorial em: 16-10-2006 
No sul do Brasil, em áreas de integração lavoura-pecuária, a época destinada ao pastejo ocorre geralmente no período de inverno-primavera e coincide com a época do ano em que o solo permanece com elevada umidade, o que pode favorecer o processo de compactação (BASSANI, 1996), prejudicando o crescimento radicular e a produtividade das culturas. Esse sistema integra as duas atividades com os objetivos de maximizar racionalmente o uso da terra (MELLO et al., 2002).

Visando à otimização do conjunto trator-semeadora, é necessário o conhecimento da força de tração exercida sobre a semeadora e o requerimento de cada tipo de mecanismo sulcador. Segundo DANIEL \& MARETTI (1990), a importância básica de avaliar a compactação do solo prende-se ao fato de a mesma oferecer resistência ao esforço tratório e ao perfeito desenvolvimento das culturas. ARAÚJO et al. (1998) identificaram que, na região oeste do Paraná, a compactação superficial do solo constitui forte restrição para o plantio direto, onde o uso de sulcadores tipo haste nas semeadoras tem se generalizado como alternativa para rompê-la. As hastes formam o sulco de semeadura com maiores profundidades do que os discos duplos, com conseqüente aumento da mobilização do solo, esforços de tração e exigência de potência nos tratores (ARAÚJO et al. (1999); OLIVEIRA et al. (2000)).

VIEIRA et al. (1998) afirmam que, quando o solo estiver úmido, podem ocorrer problemas com a haste devido à aderência do mesmo ao implemento e aos elementos de discos, e para CHANG et al. (1983), a força na barra de tração depende, entre outras variáveis, do teor de água do solo. LINDWALL \& ANDERSON (1977) comprovaram a maior capacidade de penetração das hastes, em relação aos discos duplos, em solos não-preparados e com densidade do solo superior a $1,2 \mathrm{~g} \mathrm{~cm}^{-3}$.

O objetivo deste trabalho foi avaliar a força de tração requerida por uma semeadora com dois tipos de elementos sulcadores na semeadura da soja, em áreas compactadas pelo pisoteio de animais, em sistema de integração agricultura-pecuária.

\section{MATERIAL E MÉTODOS}

Os ensaios foram realizados na Fazenda Santa Maria, no município de Santa Tereza do Oeste - PR, no período de abril de 2003 a abril de 2004.

O solo da área experimental foi classificado, conforme EMBRAPA (1999), como Latossolo Vermelho Eutroférrico, textura argilosa. Foi realizada a análise química do solo antes da implantação da espécie de cobertura (aveia-preta (Avena strigosa)), visando a identificar a necessidade ou não de calcário e conhecer os teores de nutrientes do solo na ocasião da implantação do experimento. A aveia-preta foi utilizada como espécie de forragem para o gado, sendo semeada no dia 15 de maio de 2003, na quantidade de $60 \mathrm{~kg}$ de sementes por hectare.

De acordo com análise granulométrica, o solo da área do experimento possui 13,57\% de areia, 29,31\% de silte e 57,13\% de argila, sendo considerado solo argiloso.

Foi utilizado o delineamento inteiramente casualizado em parcelas subdivididas "Split Plot", e os tratamentos principais foram compostos pelo pastejo com o solo úmido ou molhado (de friável a plástico), pastejo em solo seco (tenaz) e sem pastejo (testemunha), sendo a lotação de 26 U. A. $\mathrm{ha}^{-1}$ (unidade animal por hectare). Os tratamentos secundários foram compostos pelos elementos sulcadores da semeadora (haste e disco duplo para deposição do adubo). Cada parcela, com total de $1.600 \mathrm{~m}^{2}(50 \times 32 \mathrm{~m})$, e as subparcelas tinham dimensões de $20 \times 8 \mathrm{~m}$, com total de $160 \mathrm{~m}^{2}$.

Os animais foram conduzidos ao sistema de pastejo rotacionado, no dia 21 de julho de 2003, sendo no dia anterior determinada a massa corporal individual $(\mathrm{kg})$ de todos os animais, com média de peso de entrada no sistema de $389 \mathrm{~kg}$ e saíram do sistema no dia 8 de setembro de 2003, com peso de saída dos animais de $441 \mathrm{~kg}$, sendo, no total, 28 animais, perfazendo o total de 24 U.A. ha ${ }^{-1}$ na entrada do pastejo rotacionado e 27,5 U.A. ha $^{-1}$ na saída do pastejo rotacionado. Esses animais foram todos marcados e selecionados para que tivessem padrão de uniformidade, sendo todos provenientes de cruzamento industrial, entre as raças nelore, aberdeen angus e charolês. 
O sistema consistia de vários piquetes, caracterizando-se pela mudança periódica e freqüente dos animais de um piquete para outro, permanecendo de um a três dias, levando em consideração o manejo da forragem, para manter índice de área foliar suficiente para a rebrota da aveia, com altura entre 30 a $50 \mathrm{~cm}$. Assim, foram consideradas mais importantes a taxa de crescimento das plantas e a disponibilidade de forragem do que o tempo predeterminado de descanso.

Os animais permaneciam nesse sistema até que houvesse a ocorrência de chuvas, quando eram conduzidos para o pastejo (na parcela pastejo solo úmido do experimento), ficando nesse piquete durante o tempo considerado para que o solo estivesse úmido (estado de sazão) ou molhado, período que variava, em média, de um a três dias. Na ausência de chuva, os animais eram conduzidos para as parcelas de pastejo solo seco, permanecendo nesse piquete de acordo com o manejo da forragem, sendo, em seguida, conduzidos aos demais piquetes, onde ficavam até a próxima ocorrência de chuvas, quando eram novamente conduzidos para o tratamento de pastejo solo úmido, sendo assim realizado o sistema de pastejo rotacionado.

Os resultados obtidos na avaliação foram submetidos à análise de variância, e os contrastes entre as médias foram comparados pelo teste de Tukey, a 5\% de significância, segundo BANZATTO \& KRONKA (1995). A análise estatística foi realizada utilizando-se do programa Sisvar (FERREIRA, 2000).

O conjunto foi composto por um trator New Holland, modelo 7630 turbo (4X2 TDA), potência de 75,8 kW (103 cv) e semeadora de precisão marca Semeato, modelo PSM 102, com mecanismo dosador de sementes do tipo disco horizontal e mecanismo dosador de adubo tipo rosca semfim. A semeadora foi utilizada com os depósitos de adubos cheios, com nove linhas de semeadura, com 0,45 cm de espaçamento entre as linhas, e as sementes colocadas no mesmo sulco do adubo. Foram utilizadas duas combinações de elementos de corte de palha e deposição de adubo.

As combinações (corte da palha e sulcador de adubo) dos elementos sulcadores avaliados foram: disco de corte liso, com diâmetro de $432 \mathrm{~mm}$ e discos duplos, com diâmetro de $381 \mathrm{~mm}$ (disco) e disco de corte liso, com diâmetro de $432 \mathrm{~mm}$ e haste (facão).

O conjunto de deposição de sementes foi composto por discos duplos, com diâmetro de 381 $\mathrm{mm}$, tendo-se, após os discos, rodas calibradoras de profundidade em ambos os lados do disco e, em seguida, rodas compactadoras em formato de "V".

O conteúdo de água no solo foi determinado pela diferença de peso da amostra do solo úmido e do peso da amostra seca em estufa, a $105^{\circ} \mathrm{C}$, por $24 \mathrm{~h}$, proposto por EMBRAPA (1997). A profundidade de amostragem foi de $0-10 \mathrm{~cm}$ e de $10-20 \mathrm{~cm}$, com duas repetições por subparcela, em três períodos de observação: antes da semeadura da aveia, anterior à semeadura da soja e após a colheita da soja.

A densidade do solo foi determinada pelo método do anel volumétrico, conforme descrito por EMBRAPA (1997). A profundidade de amostragem foi de 0-10 $\mathrm{cm}$ e $10-20 \mathrm{~cm}$, com duas repetições por subparcela, em três períodos de observação: antes da semeadura da aveia (abril de 2003), anterior à semeadura da soja (novembro de 2003) e após a colheita da soja (abril de 2004).

A resistência mecânica do solo à penetração foi realizada utilizando-se de penetrógrafo SOILCONTROL - PENETROGRAPHER ${ }^{\text {PAT }}$ SC-60, perfurando em oito pontos distintos em cada subparcela e lateralmente ao local de determinação da profundidade do sulco para a deposição do adubo, à distância de 15 a $20 \mathrm{~cm}$ do sulco.

Avaliou-se a resistência do solo à penetração antes e após o pastejo do gado e após a colheita da soja em cada subparcela.

A profundidade do sulco para a deposição do adubo foi avaliada nas nove linhas de semeadura de cada subparcela, com uma repetição por linha. Para isso, retirou-se o solo do sulco de semeadura até encontrar o adubo no fundo do sulco, mensurando-se com duas réguas graduadas em 
milímetros a profundidade de deposição do adubo. Uma régua foi utilizada para ser apoiada sobre a superfície do solo no local do sulco.

Para avaliar a energia gasta no preparo do solo, foram medidas a força de tração requerida na barra de tração, a velocidade de deslocamento do conjunto de semeadura, a potência disponível na barra de tração e calculada a potência necessária no motor.

A velocidade de deslocamento do conjunto motomecanizado foi calculada pela razão da distância (20 m de distância útil mais $10 \mathrm{~m}$ de estabilização e $10 \mathrm{~m}$ para o término de avaliação) e o tempo para percorrê-la (medida com um cronômetro).

A força de tração requerida pela semeadora, em todos os tratamentos, no momento da semeadura da soja, foi medida com célula de carga Sodmex, modelo N-400, com sensibilidade de $2,156 \mathrm{mv} \mathrm{v}^{-1}$ instalada entre o trator e a semeadora. O pino que prende a barra foi retirado de modo que a barra ficasse livre, e toda a força de tração solicitada pela semeadora fosse aplicada à célula de carga.

O armazenamento de dados foi realizado com o auxílio de sistema de aquisição de dados computadorizado, modelo Micrologger CR 510 X, da Campbell Scientific, ajustado para uma freqüência de quatro amostragens por segundo. Os dados armazenados foram posteriormente transferidos em laboratório para um microcomputador, onde foram processados e analisados estatisticamente.

A partir dos dados coletados, obteve-se a força média requerida na barra de tração.

A força média de tração foi determinada pela eq.(1):

$$
F_{m}=\frac{\sum_{i=1}^{n} F i}{n}
$$

em que,

$\mathrm{F}_{\mathrm{i}}$ - força de tração instantânea, $\mathrm{kN}$;

$\mathrm{F}_{\mathrm{m}}$ - força média de tração, $\mathrm{kN}$, e

n - número de dados registrados.

A partir da força média de tração (Eq. (1)), calculou-se a potência em quilowatts $(\mathrm{kW})$ na barra de tração pela eq.(2):

$$
\mathrm{P}_{\mathrm{b}}=\mathrm{F}_{\mathrm{m}} \quad \mathrm{V}
$$

em que,

$\mathrm{P}_{\mathrm{b}}$ - potência na barra de tração, $\mathrm{kW}$;

$\mathrm{F}_{\mathrm{m}}$ - força média de tração $\mathrm{kN}$, e

$\mathrm{V}$ - velocidade média de semeadura, $\mathrm{m} \mathrm{s}^{-1}$.

A potência necessária no motor foi calculada utilizando a eq. (3), seguindo a norma ASAE D497.4 (ASAE, 1999), considerando o fator de correção para trator 4x2 com tração dianteira auxiliar ao trabalhar em solo firme.

$$
\mathrm{P}_{\mathrm{b}}=\mathrm{P}_{\mathrm{m}} \mathrm{c}
$$

em que,

$\mathrm{P}_{\mathrm{m}}$ - potência no motor do trator, $\mathrm{kW}$;

$\mathrm{P}_{\mathrm{b}}$ - potência na barra de tração, $\mathrm{kW}$, e

c - fator de correção sugerido por ASAE (1999), para estimar a potência útil na barra de tração do trator, que para solo é c $=0,639$. 


\section{RESULTADOS E DISCUSSÃO}

Os dados de densidade do solo (Tabela 1,) na camada de 0 - $10 \mathrm{~cm}$, foram maiores no sistema pastejo solo úmido do que nos demais tratamentos, podendo-se atribuir o resultado ao fato de que os maiores efeitos do pisoteio de animais são evidenciados principalmente quando o solo se encontra com umidade elevada, corroborando TANNER \& MAMARIL (1959), BETTERIDGE et al. (1999), MELLO el al. (2002) e LIMA et al. (2004).

$\mathrm{Na}$ camada de $10-20 \mathrm{~cm}$, não ocorreu diferença significativa entre os tratamentos, corroborando TORMENA et al. (2004).

TABELA 1. Densidade do solo $\left(\mathrm{kg} \mathrm{dm}^{-3}\right)$ na camada de 0-10 $\mathrm{cm}$ e $10-20 \mathrm{~cm}$, após a retirada dos animais e anterior à semeadura da soja, de acordo com os tratamentos.

\begin{tabular}{ccccccc}
\hline \multirow{2}{*}{ Camada $(\mathrm{cm})$} & \multicolumn{3}{c}{ Tratamentos } & \multirow{2}{*}{ Média } & \multirow{2}{*}{ C.V.(\%) } & \multirow{2}{*}{ DMS } \\
\cline { 2 - 6 } & Sem Pastejo & Pastejo Solo Seco & Pastejo Solo Úmido & & & \\
\hline $0-10$ & $1,22 \mathrm{~A}$ & $1,21 \mathrm{~A}$ & $1,31 \mathrm{~B}$ & 1,24 & 4,04 & 0,06 \\
$10-20$ & $1,21 \mathrm{~A}$ & $1,21 \mathrm{~A}$ & $1,24 \mathrm{~A}$ & 1,22 & 2,94 & 0,05 \\
\hline
\end{tabular}

Médias seguidas pela mesma letra maiúscula na linha não diferem entre si, pelo teste de Tukey, a 5\% de probabilidade.

Observa-se, na Figura 1 e na Tabela 2, o acentuado efeito do pisoteio do gado na resistência à penetração. Essa resistência a $5 \mathrm{~cm}$ torna-se proeminente e nota-se o afastamento entre as curvas, indicando a influência de cada tratamento, até a profundidade de $20 \mathrm{~cm}$. Pode-se dizer que os efeitos dos tratamentos são percebidos de forma sensível pelo solo até essa profundidade, permitindo, assim, delimitar a camada compactada aos $20 \mathrm{~cm}$ superficiais do solo.

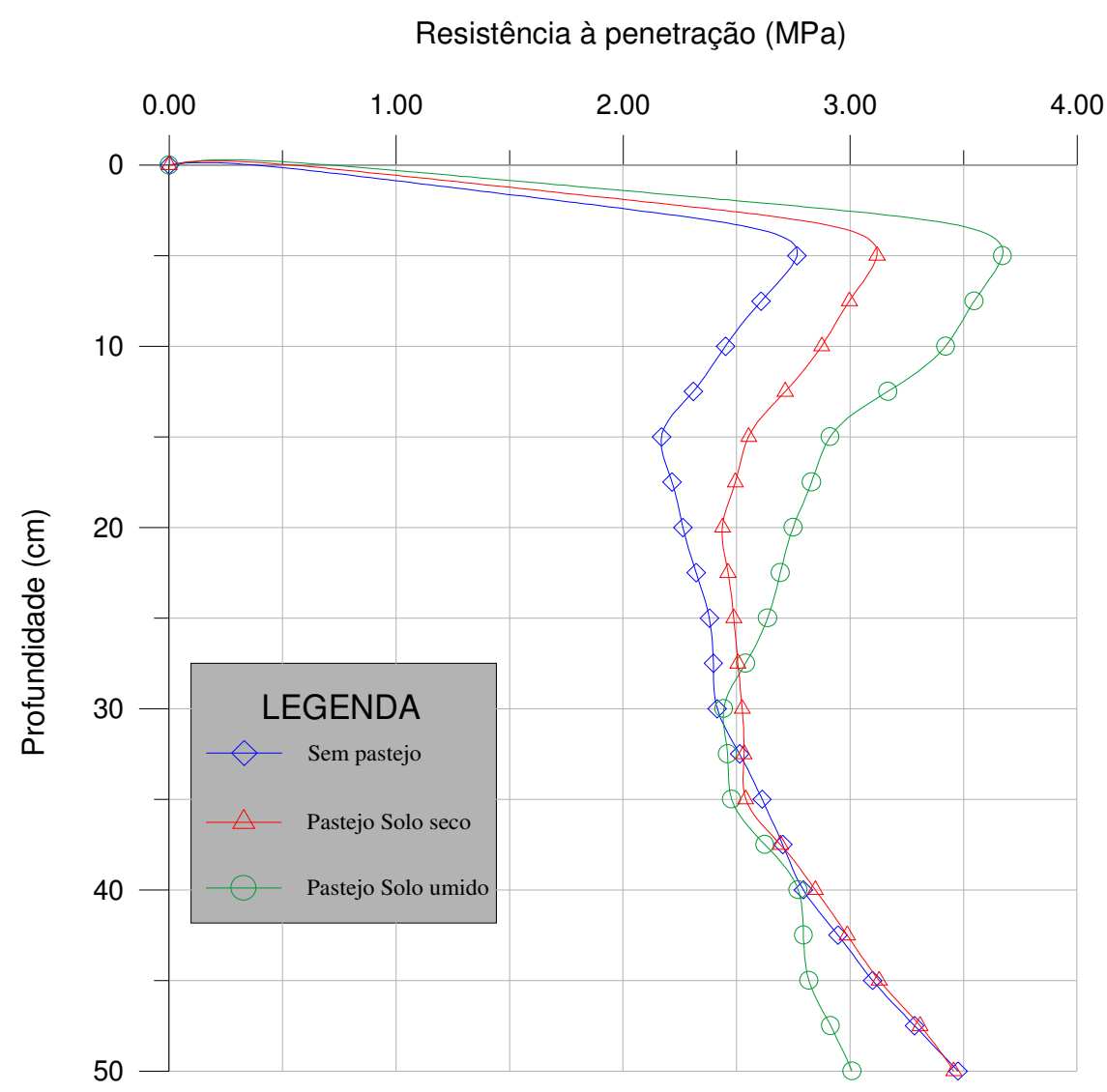

FIGURA 1. Resistência mecânica do solo à penetração (MPa), após a retirada dos animais e anterior à semeadura da soja, de acordo com os tratamentos. 
TABELA 2. Resistência do solo à penetração (MPa), após a retirada dos animais e anterior à semeadura da soja, de acordo com os tratamentos.

\begin{tabular}{cccccrc}
\hline \multirow{2}{*}{ Camada $(\mathrm{cm})$} & \multicolumn{4}{c}{ Tratamentos } & \multirow{2}{*}{ Média C.V.(\%) } & \multirow{2}{*}{ DMS } \\
\cline { 2 - 6 } & Sem Pastejo & Pastejo Solo Seco & Pastejo Solo Úmido & & & \\
\hline $0-10$ & $2,61 \mathrm{~A}$ & $3,00 \mathrm{AB}$ & $3,55 \mathrm{~B}$ & 3,05 & 14,35 & 0,55 \\
$10-20$ & $2,24 \mathrm{~A}$ & $2,55 \mathrm{~B}$ & $2,91 \mathrm{C}$ & 2,57 & 8,25 & 0,27 \\
$20-30$ & $2,39 \mathrm{~A}$ & $2,50 \mathrm{~A}$ & $2,58 \mathrm{~A}$ & 2,49 & 10,53 & 0,33 \\
\hline
\end{tabular}

Médias seguidas pela mesma letra maiúscula na coluna não diferem entre si, pelo teste de Tukey, a 5\% de probabilidade.

Observa-se, na Tabela 3, que os elementos sulcadores apresentaram diferença significativa entre si. O mecanismo sulcador de haste obteve a maior profundidade do sulco do que o mecanismo de disco, corroborando FEY (2000). No entanto, quando analisado entre os sistemas de manejo, não ocorreu diferença estatística.

TABELA 3. Profundidade do sulco para deposição do adubo $(\mathrm{cm})$ de acordo com os tratamentos.

\begin{tabular}{cccc}
\hline \multirow{2}{*}{ Tratamentos } & \multicolumn{2}{c}{ Elementos } & Médias \\
\cline { 2 - 3 } & Haste & Disco & $8,88 \mathrm{~A}$ \\
Sem pastejo & $12,50 \mathrm{Ab}$ & $5,25 \mathrm{Aa}$ & $9,13 \mathrm{~A}$ \\
Pastejo solo seco & $12,50 \mathrm{Ab}$ & $5,75 \mathrm{Aa}$ & $8,13 \mathrm{~A}$ \\
Pastejo solo úmido & $12,00 \mathrm{Ab}$ & $4,25 \mathrm{Aa}$ & \\
\hline Médias & $12,33 \mathrm{~b}$ & $5,08 \mathrm{a}$ &
\end{tabular}

Médias seguidas pela mesma letra maiúscula na coluna, e minúscula na linha, não diferem entre si, pelo teste de Tukey, a $5 \%$ de probabilidade. Média Geral = 8,71; C.V. $1(\%)=12,18$; C.V. $2(\%)=16,30$; DMS (parcela) $=1,48 ;$ DMS $($ subparcela $)=1,31$.

A profundidade média do sulco atingida pela haste foi de $12 \mathrm{~cm}$, e pelo disco $5 \mathrm{~cm}$, conforme se observa na Tabela 3.

Nas Tabelas 4; 5; 6 e 7, observa-se que, nos sistemas de pastejo, o efeito do pastejo não alterou significativamente a força de tração, a potência requerida na barra de tração pela semeadora e a potência necessária no motor; mas, na Tabela 6, pode-se observar que a velocidade de deslocamento nas áreas que foram manejadas com o mecanismo sulcador de disco, foi maior do que o mecanismo sulcador de haste, sendo estatisticamente diferente.

A maior presença de cobertura vegetal nas áreas sem pastejo pode ter alterado a relação de contato do rodado do trator com o solo, aumentando o patinamento e, conseqüentemente, diminuindo a velocidade, o que está de acordo com GABRIEL FILHO et al. (2002).

Entre os elementos sulcadores, as variáveis velocidade de semeadura, força de tração, potência requerida na barra de tração pela semeadora e potência necessária no motor apresentaram diferença estatística entre os elementos sulcadores, podendo ser observado nas Tabelas 4; 5; 6 e 7.

A semeadora equipada com o sulcador de haste necessitou de maior força de tração em relação ao de disco duplo, com aumento de cerca de 4,35 vezes. Mantida a mesma marcha e rotação inicial do motor, ocorreu diminuição de $6,4 \%$ na velocidade do conjunto com sulcador de haste em relação àquela com disco. A potência requerida na barra de tração foi maior na semeadora com sulcador de hastes. Os resultados encontrados, com relação à potência requerida, estão condizentes com COELHO (1998) e FEY (2000), em que os elementos sulcadores tipo haste apresentaram maior demanda energética, ocasionada pelo maior volume de solo mobilizado. 
TABELA 4. Valores médios de velocidade de semeadura para os tratamentos principais (pastejos com solo seco, úmido e sem pastejo) e secundários (sulcadores de hastes e discos duplos).

\begin{tabular}{cccc}
\hline \multicolumn{4}{c}{ Velocidade $\left(\mathrm{km} \mathrm{h}^{-1}\right)$} \\
Tratamentos & \multicolumn{2}{c}{ Elementos } & \\
\cline { 2 - 3 } & Haste & Disco & Médias \\
\hline Sem pastejo & $4,18 \mathrm{Aa}$ & $4,45 \mathrm{Ab}$ & $4,32 \mathrm{~A}$ \\
Pastejo solo seco & $4,27 \mathrm{Aa}$ & $4,55 \mathrm{Ab}$ & $4,41 \mathrm{~A}$ \\
Pastejo solo úmido & $4,27 \mathrm{Aa}$ & $4,60 \mathrm{Ab}$ & $4,43 \mathrm{~A}$ \\
\hline Médias & $4,24 \mathrm{a}$ & $4,53 \mathrm{~b}$ & \\
\hline
\end{tabular}

Médias seguidas pela mesma letra maiúscula na coluna, e minúscula na linha, não diferem entre si, pelo teste de Tukey, a $5 \%$ de probabilidade. Média Geral $=4,38$; C.V. $1(\%)=1,99$; C.V. $2(\%)=1,88$; DMS (parcela) $=0,12$; DMS $($ subparcela $)=0,08$.

TABELA 5. Valores médios de força de tração para os tratamentos principais (pastejos com solo seco, úmido e sem pastejo) e secundários (sulcadores de hastes e discos duplos).

\begin{tabular}{cccc}
\hline \multicolumn{3}{c}{ Força de Tração $(\mathrm{kN})$} & \\
\cline { 2 - 4 } Tratamentos & \multicolumn{2}{c}{ Elementos } & Médias \\
\cline { 2 - 4 } & Haste & Disco & $17,11 \mathrm{~A}$ \\
Sem pastejo & $27,21 \mathrm{Ab}$ & $7,01 \mathrm{Aa}$ & $16,45 \mathrm{~A}$ \\
Pastejo solo seco & $26,63 \mathrm{Ab}$ & $6,27 \mathrm{Aa}$ & $16,37 \mathrm{~A}$ \\
\hline Pastejo solo úmido & $27,35 \mathrm{Ab}$ & $5,38 \mathrm{Aa}$ &
\end{tabular}

Médias seguidas pela mesma letra maiúscula na coluna, e minúscula na linha, não diferem entre si, pelo teste de Tukey, a $5 \%$ de probabilidade. Média Geral $=16,64$; C.V. $1(\%)=9,98$; C.V. $2(\%)=6,53$; DMS (parcela) $=236,62$; DMS $($ subparcela $)=102,27$.

TABELA 6. Valores médios de potência requerida na barra de tração para os tratamentos principais (pastejos com solo seco, úmido e sem pastejo) e secundários (sulcadores de hastes e discos duplos).

\begin{tabular}{cccc}
\hline \multicolumn{3}{c}{ Potência requerida na barra de tração $(\mathrm{kW})$} & \\
\cline { 2 - 3 } Tratamentos & Haste & Disco & \multirow{2}{*}{ Médias } \\
\hline Sem pastejo & $31,56 \mathrm{Ab}$ & $9,27 \mathrm{Aa}$ & $20,41 \mathrm{~A}$ \\
Pastejo solo seco & $31,58 \mathrm{Ab}$ & $7,92 \mathrm{Aa}$ & $19,75 \mathrm{~A}$ \\
Pastejo solo úmido & $32,34 \mathrm{Ab}$ & $6,87 \mathrm{Aa}$ & $19,60 \mathrm{~A}$ \\
\hline Médias & $31,83 \mathrm{~b}$ & $8,02 \mathrm{a}$ & \\
\hline
\end{tabular}

Médias seguidas pela mesma letra maiúscula na coluna, e minúscula na linha, não diferem entre si, pelo teste de Tukey, a $5 \%$ de probabilidade. Média Geral $=19,92$; C.V. $1(\%)=9,64$; C.V. $2(\%)=8,69$; DMS (parcela) $=2,68$; DMS $($ subparcela $)=1,60$.

TABELA 7. Valores médios de potência necessária no motor para os tratamentos principais (pastejos com solo seco, úmido e sem pastejo) e secundários (sulcadores de hastes e discos duplos).

\begin{tabular}{cccc}
\hline \multicolumn{3}{c}{ Potência Necessária no Motor $(\mathrm{kW})$} & \\
\cline { 2 - 3 } Tratamentos & \multicolumn{2}{c}{ Elementos } & \multirow{2}{*}{ Médias } \\
\cline { 2 - 3 } & $49,39 \mathrm{Ab}$ & $14,51 \mathrm{Aa}$ & $31,95 \mathrm{~A}$ \\
Sem pastejo & $49,42 \mathrm{Ab}$ & $12,39 \mathrm{Aa}$ & $30,90 \mathrm{~A}$ \\
Pastejo solo seco & $50,62 \mathrm{Ab}$ & $10,74 \mathrm{Aa}$ & $30,68 \mathrm{~A}$ \\
\hline Pastejo solo úmido & $49,81 \mathrm{~b}$ & $12,55 \mathrm{a}$ & \\
\hline Médias &
\end{tabular}

Médias seguidas pela mesma letra maiúscula na coluna, e minúscula na linha, não diferem entre si, pelo teste de Tukey, a $5 \%$ de probabilidade. Média Geral = 31,18; C.V. $1(\%)=9,64 ;$ C.V. $2(\%)=8,68$; DMS (parcela) = 4,20; DMS $($ subparcela $)=2,50$. 


\section{CONCLUSÕES}

O pastejo em área de integração lavoura-pecuária altera as características físicas do solo, sendo esse efeito mais acentuado em condições de pastejo com solo úmido.

Houve o efeito do pisoteio do gado em compactar o solo na camada até os $5 \mathrm{~cm}$ iniciais.

A força de tração, a potência requerida na barra de tração pela semeadora e a potência necessária no motor foram maiores quando foi utilizado o mecanismo sulcador tipo haste, enquanto a velocidade de deslocamento foi maior quando se utilizou o mecanismo sulcador de disco.

A ação do pisoteio do gado sobre o solo alterou as condições de densidade e resistência à penetração, entretanto não foi suficiente para interferir na demanda de potência nas três condições estudadas. As semeadoras com sulcadores de disco exerceram menor força de tração, e a velocidade de deslocamento do conjunto foi maior, cerca de $6,4 \%$, em relação ao sulcador de haste.

\section{REFERÊNCIAS}

ASAE D 497.4. Agricultural Machinery Management. In: ASAE standards Jan. 99. St. Joseph, 1999.

ARAÚJO, A.G.; CASÃO JUNIOR, R.; RALISCH, R.; SIQUEIRA, R. Mobilização de solo e emergência de plantas no plantio direto de soja (Glycine max L.) e milho (Zea mays L.) em solos argilosos. Engenharia Agrícola, Jaboticabal, v.19, n.2, p. 226-37, 1999.

ARAÚJO, A.G.; CASÃO JUNIOR, R.; MEDEIROS, G.B.; CASTRO FILHO, C.; DORETTO, M.; BERTÉ, A.; CAVIGLIONE, J.H.; FIGUEIREDO, P.R.A. Identificação das restrições para expansão do plantio direto na região da represa de Itaipu. In: ENCONTRO LATINOAMERICANO SOBRE PLANTIO DIRETO NA PEQUENA PROPRIEDADE, 1998, Pato Branco. Anais... Pato Branco: Instituto Agronômico do Paraná, 1998. 1 CD-ROM

BANZATTO, D.A.; KRONKA, S.N. Experimentação Agrícola. UNESP: Jaboticabal, 1995. 247 p.

BASSANI, H.J. Propriedades físicas induzidas pelo plantio direto e convencional em área pastejada e não pastejada. 1996. 90 f. Dissertação (Mestrado) - Universidade Federal de Santa Maria, Santa Maria, 1996.

BETTERIDGE, K.; MACKAY, A.D.; SHEPHERD, T.G.; BARKER, D.J.; BUDDING, P.J.; DEVANTIER, B.P.; COSTALL, D. A. Effect of cattle and sheep treading on surface configuration of a sedimentary hill soil. Australian Journal of Soil Research, Collinwood, v.37, p.743-60, 1999.

CHANG, C.S.; PORTELLA, J.A.; KUMAGAI, I. Exigência da força nos sistemas que utilizam tração para o plantio direto. In: CONGRESSO BRASILEIRO DE ENGENHARIA AGRÍCOLA, 13., 1983, Rio de Janeiro. Resumos... Rio de Janeiro: Sociedade Brasileira de Engenharia Agrícola, 1983. p.130.

COELHO, J.L.D. Avaliação de elementos sulcadores para semeadoras-adubadoras utilizadas em sistemas conservacionistas de manejo do solo. 1998. Dissertação (Mestrado em Máquinas Agrícolas) - Universidade Estadual de Campinas, Campinas, 1998.

DANIEL, L.A.; MARETTI, H.J. Avaliação de camadas de solo compactado e análise de crescimento de plantas. In: CICLO DE ESTUDOS SOBRE MECANIZAÇÃO AGRÍCOLA, 4., 1990, Campinas. Anais... Campinas: Fundação Cargill, 1990. p.23-33.

EMBRAPA. Centro Nacional de Pesquisa de Solos. Manual de análise de solo. 2.ed. Rio de Janeiro, 1997. 212 p.

EMBRAPA. Centro Nacional de Pesquisa de Solos. Sistema brasileiro de classificação de solo. Rio de Janeiro, 1999. 412 p.

FERREIRA, D. F. Manual do sistema Sisvar para Análises Estatísticas. Lavras: UFLA, 2000. $63 \mathrm{p}$. 
FEY, E. Desempenho de sulcadores utilizados em semeadora para plantio direto sob a palha, num solo argiloso com diferentes teores de água. 2000. 76 f. Dissertação (Mestrado em Máquinas Agrícolas) - Universidade Estadual do Oeste do Paraná, Cascavel, 2000.

GABRIEL FILHO, A.; SILVA, S.L.; MODOLO, A.J.; DYKSTRA, M. Desempenho operacional de trator em solo com três tipos de Cobertura vegetal. In: CONGRESSO BRASILEIRO DE ENGENHARIA AGRÍCOLA, 31., 2002, Salvador. Anais... Salvador: Sociedade Brasileira de Engenharia Agrícola, 2002. 1 CD-ROM.

KOCHHANN, R.A.; DENARDIN, J.E.; BERTON, A.L. Compactação e descompactação de solos. Passo Fundo: Embrapa Trigo, 2000. 20 p.

LINDWALL, C.W.; ANDERSON, D.T. Effects of different seeding machines on spring wheat production under various condition of stubble residue and soil compactation in no-till rotataions. Canadian Journal of Soil Science, Ottawa, v.57, n.2, p.81-91, 1977.

LIMA, C.L.R.; SILVA, A.P.; IMHOFF, T.P.; LEÃO, T.P. Compressibilidade de um solo sob sistemas de pastejo rotacionado intensivo irrigado e não- irrigado. Revista Brasileira de Ciência do Solo, Viçosa, v.28, n.6, nov/dez. 2004.

MELLO, L.M.M.; YANO, E.H.; NARIMATSU, K.C.P., TAKAHASHI, C.M.; BORGHI, E. Integração agricultura-pecuária em plantio direto: produção de forragem e resíduo de palha após pastejo. Engenharia Agrícola, Jaboticabal, v.24, n.1, p.121-9, jan./abr. 2004.

OLIVEIRA, M.F.B.; SIQUEIRA, R.; RALISCH, R.; ARAÚJO, A.G.; CASÃO JUNIOR, R. Mobilização do solo por hastes sulcadoras de semeadoras-adubadoras de plantio direto.In: CONGRESSO BRASILEIRO DE ENGENHARIA AGRÍCOLA, 29., 2000, Fortaleza. Anais... Fortaleza: Sociedade Brasileira de Engenharia Agrícola, 2000. 1 CD-ROM.

OLIVEIRA, G.C.; DIAS JUNIOR, M.S.; CURI, N.; RESCK, D.V.S. Compressibilidade de um Latossolo Vermelho argiloso de acordo com a tensão de água no solo, uso e manejo. Revista Brasileira de Ciência do Solo, Campinas, v.27, p.773-81, 2003.

TANNER, C.B.; MAMARIL, C.P. Pasture soil compaction by animal traffic. Agronomy Journal, Madison, v.51, p.329-31, 1959.

TORMENA, C.A.; VIDIGAL FILHO, P.S.; GONÇALVES, A.C.A.; ARAÚJO, M.A.; PINTRO, J.C. Influência de diferentes tipos de preparo do solo nas propriedades físicas de um Latossolo distrófico. Revista Brasileira de Engenharia Agrícola e Ambiental, Campina Grande, v.8, n.1, p.65-71, 2004.

VIEIRA, C.P.; MESQUITA, C.M.; HERNANI, L.C. Mecanização. Sistema plantio direto. O produtor pergunta, a EMBRAPA responde. Brasília: EMBRAPA - SPI; Dourados: EMBRAPA CPAO, 1998. cap.13, p.151.

VOORHESS, W.B.; JOHNSON, J.F.; RANDALL, G.W.; NELSON, W.W. Corn growth and yield as affected by surface and subsoil compaction. Agronomy Journal, Madison, v.81, p.294-303, 1989. 